\title{
Gender Differences and Work-Family Conflicts among Emergency Physicians with Intention to Leave
}

\author{
Yi-Fang Wu $\mathbb{D}^{1},{ }^{1}$ Po-Chang Wang $\mathbb{D}^{\mathrm{D}}{ }^{2}$, and Yi-Chuan Chen ${ }^{1}{ }^{1}$ \\ ${ }^{1}$ Department of Emergency Medicine, Chang Gung Memorial Hospital, Puzi City, Chiayi, Taiwan \\ ${ }^{2}$ Department of Cardiology, Chang Gung Memorial Hospital, Puzi City, Chiayi, Taiwan \\ Correspondence should be addressed to Yi-Chuan Chen; giomacky@gmail.com
}

Received 14 September 2018; Accepted 23 October 2018; Published 29 October 2018

Academic Editor: Jeffrey R. Avner

Copyright (c) 2018 Yi-Fang Wu et al. This is an open access article distributed under the Creative Commons Attribution License, which permits unrestricted use, distribution, and reproduction in any medium, provided the original work is properly cited.

\begin{abstract}
Backgrounds. The objective of this study was to investigate the relationships among intention to leave, emergency physician clinical activities, work-family conflicts, and gender differences in emergency physicians (EPs). Methods. The survey instrument was a selfadministered questionnaire containing basic demographic information and characteristics of clinical activities. The work-family conflicts were assessed by the Chinese version of the work-family conflict (WIF) scale. The questionnaires were mailed to boardcertified EPs between January 2014 and August 2014. Student's $t$-test, Chi-square test, and one-way analysis of variance (ANOVA) were used to test the difference between subgroups. Logistic regression analysis was performed to determine the factors associated with intention to leave and gender differences. Results. The study included 222 respondents for analysis after exclusions. Compared with physicians not planning to leave, those planning to leave ED practice showed higher dissatisfaction with their clinical work hours $(50.0 \%$ versus $31.4 \%, \mathrm{p}=0.035)$ and night/day shift ratio $(52.9 \%$ versus $31.0 \%, \mathrm{p}=0.013)$ and tended to work with night/day shift ratio exceeding $40 \%$ (67.6\% versus $45.7 \%, \mathrm{p}=0.019)$. Female physicians were more likely to leave ED practice (females versus males, $26.5 \%$ versus $10.1 \%, p=0.008)$. A significantly higher level of WIF scale was noted in the group with intention to leave ED practice ( $3.7 \pm 0.6$ versus $3.3 \pm 0.7, \mathrm{p}=0.001)$. Conclusions. Females and EPs with higher level of WIF scale were more likely to leave emergency clinical practice. Instead of the number of clinical practice hours, the satisfaction with the clinical work hours and night shift frequency were significantly associated with the intention to leave.
\end{abstract}

\section{Introduction}

The physical and emotional demands of clinical practice have made it a difficulty for emergency physicians (EPs) to maintain it as a specialty for their entire career [1-4]. Psychological distress and burnout are prevalent among EPs [5-8]. In previous studies, excessive clinical work, rotating shifts, unpredictable clinical outcomes, and work-family conflicts were the related stress factors $[7,9]$, which eventually led to planned reduction of clinical work and intention to leave [7, 10]. EPs have a higher probability of leaving their specialties than other specialists [11]. After leaving, the EPs either opted for retirement or pursued non-emergency clinical practice, administration, research, or teaching [12]. According to a previous study, approximately $13 \%$ of board-certified EPs turned to non-emergency clinical practice [12]. Although the proportion of female EPs has increased over the years, culture values associated with traditional gender roles still exist in Asia and North America. Females are expected to take more responsibility for household work, and although female employees spend more time on housework than male employees, the demands and expectations from clinical work are the same for both genders [13]. Females and males could have different expectations from their career and may encounter different problems in the course of their attempts to keep a balance between work and family. However, studies on how intention to leave (ITL) of EPs varies between the genders are limited.

Herein, we aimed to investigate the gender differences associated with ITL, EP clinical activities, and work-family conflicts. 


\section{Methods}

2.1. Study Design and Population. The study consisted of a survey of EPs in Taiwan regarding the gender differences in the workload, work-family conflicts, and the intention to leave the emergency department (ED) practice within one year. The aim of this study was to survey the relationship among intentions to leave, work-family conflict, and gender differences. The survey instrument was a self-administered questionnaire containing 76 questions. Questions in this questionnaire were developed and adjusted after consultation with 20 EPs. Basic demographic information, including age, gender, marital status, and the number of children, was obtained. Characteristics of ED clinical activities, including clinical practice work hours per month, shift duration, night shifts, holiday shifts, teaching activity hours, administrative work, satisfaction with ED clinical practice, and finances, were obtained

The work-family conflicts were measured using the Chinese version of the work-family conflict scale (Carlson, Kacmar, and Williams, 2000), which had revealed good reliability and validity in the previous studies and was authorized by the Chinese author [14-16]. The scale comprises 18 items, and work-family conflict from both perspectives-work interference with family (WIF scale) and family interference with work (FIW scale) - was measured by nine items. Every three items represent three dimensions of work-family conflict, including time, strain, and behavior-based interference. Each of the items was scored on a 5-point Likert scale; 1 point indicates never and 5 points indicate always. Higher scores indicate higher levels of conflict.

The questionnaires were mailed to board-certified EPs working in ED of 27 hospitals in Taiwan, including medical centers and local hospitals, between January 2014 and August 2014. The questionnaires were collected by stamped return envelopes. Respondents who failed to answer more than $95 \%$ of the questionnaire were excluded from the survey. Consequently, the study protocol was approved by our institutional review board, and informed consent was obtained from each included EP.

The primary aim was to investigate the factors associated with ITL and gender. The secondary aim was to investigate the correlation of ITL and gender with the work-family conflict scale.

2.2. Statistical Analysis. All analyses were conducted using SPSS 16.0 for Windows. Student's $t$-test and Chi-square test were used to test the differences between the two groups. The difference was considered significant if $\mathrm{p}$ value was less than 0.05 . A sample of 216 achieved a power of $80 \%$ for detecting a difference in proportions of 0.3 in the main effects of gender between the non-ITL group and the ITL group at a two-sided $p$ value of 0.05 [17]. A logistic regression model was then developed. All variables with $\mathrm{p}$ value $<0.25$ in the univariate analysis were entered into a multivariable logistic regression model [18]. Logistic regression models were fitted using intention to leave (ITL) and gender as a dependent variable. A p value $<0.05$ was considered significant.

\section{Results}

Responses were received from 237 emergency physicians surveyed. Fifteen of the 237 survey respondents who failed to answer more than $95 \%$ of the questionnaire were excluded from the survey, leaving 222 respondents eligible for analysis. In our study, Cronbach's alpha coefficient of work-family conflict scale was 0.926 .

The descriptive statistics of the study population are shown in Table 1 . More than $80 \%$ of the EPs were below 45 years of age, and $87.4 \%$ of the EPs were men. Approximately $50 \%$ practiced in local hospitals, and approximately $30 \%$ of the EPs worked more than 180 hours a month in clinical ED activities. Nearly $50 \%$ of these took more than $40 \%$ of all shifts as night shifts. Overall, more than $60 \%$ planned to leave ED practice after 50 years of age, and $15.3 \%$ planned to leave ED practice within one year.

Two dichotomized variables were then created for the secondary outcome analysis on characteristics associated with EPs who planned to leave ED practice within one year (Table 2). Gender, age, and satisfaction with the work clinical hours and night shifts were significantly related to ITL within one year in ED practice. Female EPs and EPs aged $\leq 35$ years were more likely to leave ED practice. EPs planning to leave ED practice were predominantly unsatisfied with their work clinical hours and night shifts and tended to work with night/day shift ratio exceeding $40 \%$. In addition, the lower financial compensation and financial compensation bias were significantly associated with ITL. EPs who planned to retire before 45 years of age accounted for a significant percentage of EPs with ITL.

We found several gender-related differences in EPs in the present survey (Table 3). Female EPs were younger and had shorter ED practice duration than male EPs. The mean income of female EPs was less, despite the fact that there was no significant difference in ED clinical work time per month between male and female EPs; thus, a significantly higher rate of ITL was noted among female EPs. Only 35.7\% female EPs had children, while $72.2 \%$ male EPs had children.

In Table 4, we present results from the analysis of relationship between work-family conflict and the intention to leave ED practice within one year. A significantly higher level of work interference with family scale (WIF scale) was noted in individuals with intention to leave ED practice. The results showed a higher score on time-based and strain-based interference in reviewing the three dimensions of WIF scale. As in WIF scale, a significantly higher level of the time-based interference was noted in FIW scale as well. The FIW conflict was significantly lower in the group of clinical work hours less than 120 hours per month $(2.4 \pm 0.8$ versus $2.8 \pm 0.6, \mathrm{p}<0.05)$. There were no gender differences in work-family conflict in ED physicians (Table 5$)$. WIF conflict $(2.6 \pm 1.0$ versus $3.4 \pm$ $0.7, \mathrm{p}<0.05)$ and FIW conflict $(2.1 \pm 0.6$ versus $2.8 \pm 0.7, \mathrm{p}$ $<0.01)$ were significantly lower in physicians aged more than 55 years. Both WIF conflict $(\mathrm{p}<0.001)$ and FIW conflict $(\mathrm{p}<$ 0.01 ) were significantly higher when EPs felt unsatisfied with clinical work hours and financial compensation fairness. WIF conflict was higher when EPs were unsatisfied with night shift frequency $(\mathrm{p}=0.001)$. 
TABLE 1: The characteristics of the study population.

\begin{tabular}{|c|c|c|}
\hline Descriptive statistics & $\begin{array}{l}\text { Number of respondents } \\
\qquad \mathrm{N}=222\end{array}$ & $\%$ \\
\hline \multicolumn{3}{|l|}{ Age group } \\
\hline$\leq 30$ & 16 & $7.20 \%$ \\
\hline $31-35$ & 70 & $31.50 \%$ \\
\hline $36-40$ & 61 & $27.50 \%$ \\
\hline $41-45$ & 37 & $16.70 \%$ \\
\hline $46-50$ & 18 & $8.10 \%$ \\
\hline$>50$ & 20 & $9.00 \%$ \\
\hline Mean \pm SD & $39.0 \pm 7.6$ years & \\
\hline \multicolumn{3}{|l|}{ Gender } \\
\hline Male & 194 & $87.40 \%$ \\
\hline Female & 28 & $12.60 \%$ \\
\hline \multicolumn{3}{|c|}{ ED practice hospital level } \\
\hline Medical center & 108 & $48.65 \%$ \\
\hline Local hospital & 114 & $51.35 \%$ \\
\hline \multicolumn{3}{|l|}{ Shift length } \\
\hline $8 \mathrm{~h}$ & 31 & $14 \%$ \\
\hline $12 \mathrm{~h}$ & 110 & $49.50 \%$ \\
\hline Mixed shifts & 76 & $34.20 \%$ \\
\hline Others & 5 & $2.30 \%$ \\
\hline \multicolumn{3}{|c|}{ Clinical work time per month (hours) } \\
\hline$\leq 120$ & 19 & $8.60 \%$ \\
\hline $121-140$ & 21 & $9.50 \%$ \\
\hline $141-160$ & 49 & $22.10 \%$ \\
\hline $161-180$ & 67 & $30.20 \%$ \\
\hline $181-200$ & 50 & $22.50 \%$ \\
\hline$>200$ & 16 & $7.20 \%$ \\
\hline \multicolumn{3}{|l|}{ Night/day shift ratio } \\
\hline Day shift only & 16 & $7.20 \%$ \\
\hline$<20 \%$ & 29 & $13.10 \%$ \\
\hline $21-40 \%$ & 68 & $30.60 \%$ \\
\hline $41-60 \%$ & 75 & $33.80 \%$ \\
\hline $61-70 \%$ & 15 & $6.80 \%$ \\
\hline$>70 \%$ & 19 & $8.60 \%$ \\
\hline \multicolumn{3}{|c|}{ Weekend shifts per month } \\
\hline $1-3$ & 33 & $14.90 \%$ \\
\hline $4-6$ & 178 & $80.20 \%$ \\
\hline$>6$ & 11 & $5.00 \%$ \\
\hline \multicolumn{3}{|c|}{ Financial compensation per month $(10,000$ NTD $)$} \\
\hline$<30$ & 100 & $45.00 \%$ \\
\hline $30-40$ & 115 & $51.80 \%$ \\
\hline$>40$ & 7 & $3.20 \%$ \\
\hline \multicolumn{3}{|l|}{ Marital status } \\
\hline Married & 178 & $80.18 \%$ \\
\hline Others & 44 & $19.82 \%$ \\
\hline \multicolumn{3}{|l|}{ Children } \\
\hline Yes & 150 & $67.60 \%$ \\
\hline No & 72 & $32.40 \%$ \\
\hline \multicolumn{3}{|c|}{ Intention to leave within one year } \\
\hline Yes & 34 & $15.30 \%$ \\
\hline No & 188 & $84.70 \%$ \\
\hline
\end{tabular}

TABle 1: Continued.

\begin{tabular}{lcc}
\hline Descriptive statistics & $\begin{array}{c}\text { Number of respondents } \\
\mathrm{N}=222\end{array}$ & $\%$ \\
\hline Retirement age preference (years old) & \\
$<45$ & 30 & $13.50 \%$ \\
$46-50$ & 46 & $20.70 \%$ \\
$51-55$ & 63 & $28.40 \%$ \\
$>55$ & 83 & $37.40 \%$ \\
\hline
\end{tabular}

SD: standard deviation; ED: emergency department; NTD: New Taiwan dollars.

Table 6 summarizes the results of logistic regression for factors associated with intention to leave. After entering all the variables with $\mathrm{p}$ value $<0.25$ in Tables 2 and 4 , retirement preference before 45 years of age (adjusted odds ratio [OR], 10.51; 95\% confidence interval [CI]: 3.99-27.68), night/day shift ratio $>40 \%$ (OR, 2.70; 95\% CI: 1.11-6.57), and timebased family interference with work (FIW) (OR, 4.56; 95\% CI: 1.68-12.37) were associated with ITL. Table 7 summarizes the results of logistic regression for factors associated with gender differences. Age below 35 years (OR, 3.17; 95\% CI: 1.10-9.11), shift length of 12 hours (OR, 5.67; 95\% CI: 1.96-16.39), and EPs with children (OR, 0.18; 95\% CI: 0.06-0.52) were associated with gender differences.

\section{Discussion}

4.1. The Attrition and ITL of Emergency Physicians. The ITL rate of EPs ranges from $12 \%$ to $21.4 \%$ per year $[7,19]$. Frequent ITL from the profession may eventually cause increased attrition of EPs. The attrition rate within 2 years since training graduation was $6.5 \%$, and the estimated EP attrition rate was $1.7 \%$ per year in USA [12]. Similar results were noted in Taiwan; the annual attrition rate was $1.83 \%$ [11].

Our study showed that $15.3 \%$ of the respondents had ITL within one year, and $34.2 \%$ planned to retire before 50 years of age. EPs in Taiwan in our study were younger compared to those in previous studies conducted in USA. The mean age of our respondents was $39.0 \pm 7.6$ years; $66 \%$ of our respondents were aged less than 40 years. The mean age was $42.5 \pm 6.0$ years, and $34 \%$ of EPs were less than 39 years of age in the study of Lynnette Doan-Wiggins et al. in 1995 [20]. The mean age of EPs was $49.9 \pm 10.5$ years in a study conducted in 2004 in USA [21]. Younger mean age of EPs in our present study than other studies may result from the shorter duration, since we had board-certified EPs in Taiwan (the American Board of Emergency Medicine was incorporated in 1976 and Taiwan Society of Emergency Medicine in 1994). Another explanation is that, compared with surgeons and radiologists in Taiwan, the nonfailure rate for EPs after 10 years of practice is significantly decreased [11]. The trend of decrease in nonfailure rate was not noted in other regions, which showed that the cumulative and annual attrition rate did not rise rapidly until 30 years since training graduation [12]; these findings may indicate a shorter career life of EPs in Taiwan. 
TABLE 2: Characteristics associated with emergency physicians who planned to leave emergency department (ED) practice within one year.

\begin{tabular}{|c|c|c|c|c|c|}
\hline \multicolumn{6}{|c|}{ Intention to leave ED practice within one year } \\
\hline & \multicolumn{2}{|c|}{ NO } & \multicolumn{2}{|c|}{ Yes } & \multirow[t]{2}{*}{$\mathrm{p}$} \\
\hline & N. & $\%$ & $\mathrm{~N}$ & $\%$ & \\
\hline \multicolumn{6}{|l|}{ Gender } \\
\hline Male & 169 & $89.90 \%$ & 25 & $73.50 \%$ & \multirow{2}{*}{0.008} \\
\hline Female & 19 & $10.10 \%$ & 9 & $26.50 \%$ & \\
\hline \multicolumn{6}{|c|}{ ED practice hospital level } \\
\hline Medical center & 91 & $48.40 \%$ & 17 & $50.00 \%$ & \multirow{2}{*}{0.86} \\
\hline Local hospital & 97 & $51.60 \%$ & 17 & $50.00 \%$ & \\
\hline \multicolumn{6}{|l|}{ Age } \\
\hline Mean \pm SD & \multicolumn{2}{|c|}{$39.6 \pm 7.6$} & \multicolumn{2}{|c|}{$36.0 \pm 7.0$} & 0.012 \\
\hline \multicolumn{6}{|c|}{ Age group (years) } \\
\hline$\leq 35$ & 64 & $34.00 \%$ & 22 & $64.70 \%$ & \multirow{2}{*}{0.001} \\
\hline$>35$ & 124 & $66.00 \%$ & 12 & $35.30 \%$ & \\
\hline \multicolumn{6}{|c|}{ Clinical work time per month (hours) } \\
\hline$>180$ & 55 & $29.30 \%$ & 11 & $32.40 \%$ & \multirow{2}{*}{0.72} \\
\hline Less than 180 & 133 & $70.70 \%$ & 23 & $67.60 \%$ & \\
\hline \multicolumn{6}{|c|}{ Satisfaction with clinical work hours } \\
\hline Yes & 129 & $68.60 \%$ & 17 & $50.00 \%$ & \multirow{2}{*}{0.035} \\
\hline No & 59 & $31.40 \%$ & 17 & $50.00 \%$ & \\
\hline \multicolumn{6}{|c|}{ Satisfaction with night shift amount } \\
\hline Yes & 127 & $69.00 \%$ & 16 & $47.10 \%$ & \multirow{2}{*}{0.013} \\
\hline No & 57 & $31.00 \%$ & 18 & $52.90 \%$ & \\
\hline Night/day shif & & & & & \\
\hline$\leq 40 \%$ & 102 & $54.30 \%$ & 11 & $32.40 \%$ & 019 \\
\hline$>40 \%$ & 86 & $45.70 \%$ & 23 & $67.60 \%$ & 0.019 \\
\hline Weekend shift & & & & & \\
\hline $1-4$ shifts & 88 & $46.80 \%$ & 16 & $48.50 \%$ & 086 \\
\hline$\geq 5$ shifts & 100 & $53.20 \%$ & 17 & $51.50 \%$ & 0.80 \\
\hline Shift length & & & & & \\
\hline $12 \mathrm{~h}$ & 91 & $48.40 \%$ & 19 & $55.90 \%$ & 0.42 \\
\hline others & 97 & $51.60 \%$ & 15 & $44.10 \%$ & \\
\hline Financial com & er mo & & & & \\
\hline$\leq 300,000$ & 76 & $40.40 \%$ & 22 & $64.70 \%$ & 0.009 \\
\hline$>300,000$ & 112 & $59.60 \%$ & 12 & $35.30 \%$ & 0.009 \\
\hline Financial com & airnes & & & & \\
\hline Yes & 104 & $55.60 \%$ & 12 & $35.30 \%$ & 0020 \\
\hline No & 83 & $44.40 \%$ & 22 & $64.70 \%$ & 0.029 \\
\hline Administratio & & & & & \\
\hline Yes & 43 & $23.20 \%$ & 9 & $26.50 \%$ & 068 \\
\hline No & 142 & $76.80 \%$ & 25 & $73.50 \%$ & 0.08 \\
\hline Teaching activ & th (he & & & & \\
\hline$\geq 40$ & 11 & $5.90 \%$ & 3 & $8.80 \%$ & 0.46 \\
\hline$<40$ & 177 & $94.10 \%$ & 31 & $91.20 \%$ & 0.40 \\
\hline Retirement age & (yea & & & & \\
\hline$\leq 45$ & 16 & $8.50 \%$ & 14 & $41.20 \%$ & \\
\hline $46-50$ & 41 & $21.80 \%$ & 5 & $14.70 \%$ & $<0001$ \\
\hline $51-55$ & 53 & $28.20 \%$ & 10 & $29.40 \%$ & \\
\hline$>55$ & 78 & $41.50 \%$ & 5 & $14.70 \%$ & \\
\hline Marital status & & & & & \\
\hline Married & 155 & $82.40 \%$ & 23 & $67.60 \%$ & 0.046 \\
\hline Others & 33 & $17.60 \%$ & 11 & $32.40 \%$ & \\
\hline Children & & & & & \\
\hline Yes & 133 & $70.70 \%$ & 17 & $50.00 \%$ & 0.017 \\
\hline No & 55 & $29.30 \%$ & 17 & $50.00 \%$ & $0.01 /$ \\
\hline
\end{tabular}

ED: emergency department; SD: standard deviation; NTD: New Taiwan dollars. 
TABLE 3: Gender differences in emergency physicians.

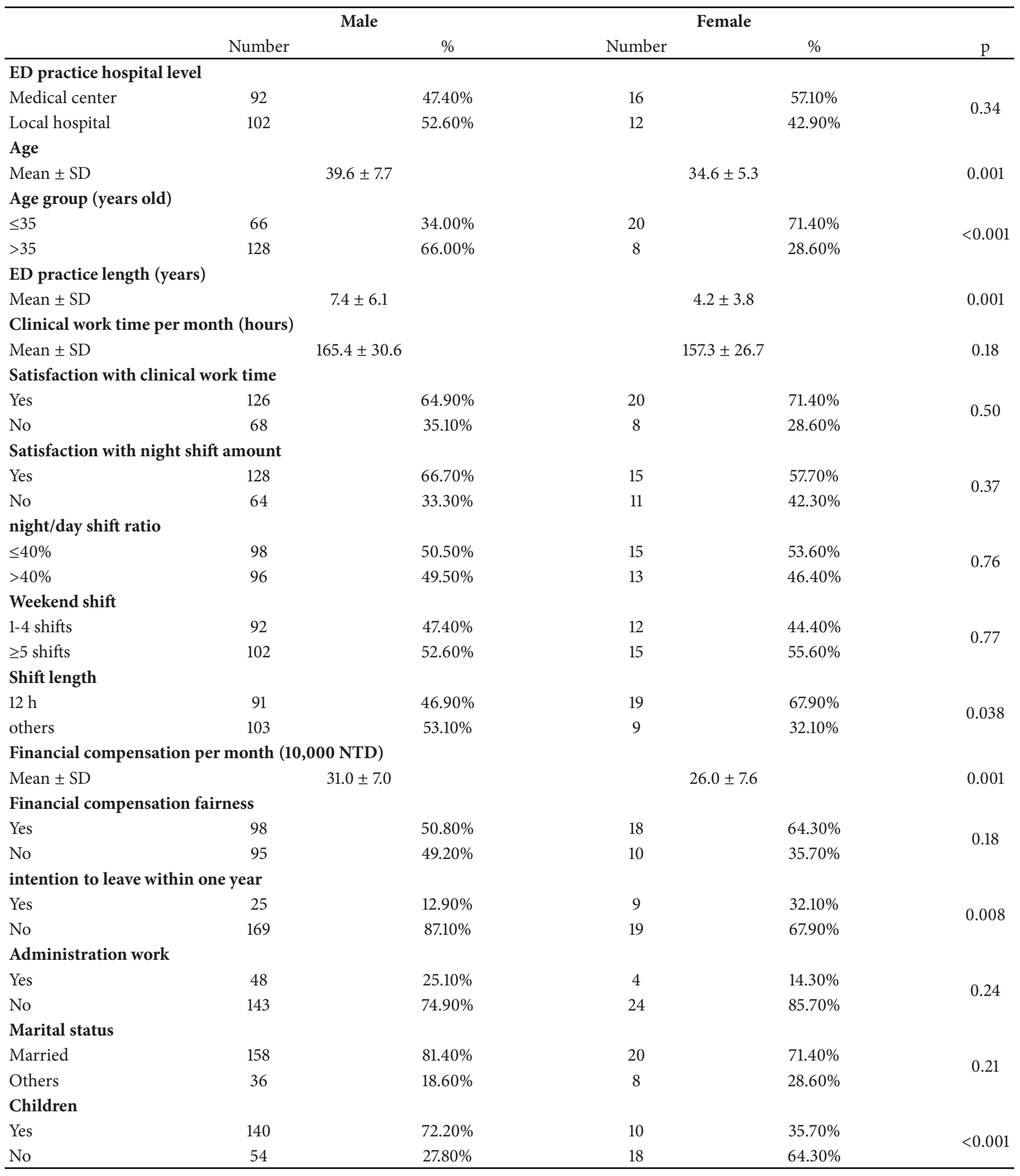

ED: emergency department; SD: standard deviation; NTD: New Taiwan dollars. 
TABLE 4: Relationship between work-family conflict and intention to leave emergency department (ED) practice within one year.

\begin{tabular}{|c|c|c|c|}
\hline \multirow{3}{*}{ Work-family conflict } & \multicolumn{2}{|c|}{ Intention to leave within one year } & \multirow{3}{*}{$\mathrm{p}$} \\
\hline & Yes & No & \\
\hline & Mean \pm SD & Mean \pm SD & \\
\hline Work interference with family (WIF) & $3.7 \pm 0.6$ & $3.3 \pm 0.7$ & 0.001 \\
\hline Time based & $4.0 \pm 0.8$ & $3.5 \pm 0.8$ & 0.003 \\
\hline Strain based & $3.9 \pm 0.7$ & $3.3 \pm 0.9$ & $<0.001$ \\
\hline Behavior based & $3.3 \pm 0.8$ & $3.1 \pm 0.8$ & 0.11 \\
\hline Family interference with work (FIW) & $3.0 \pm 0.6$ & $2.7 \pm 0.7$ & 0.06 \\
\hline Time based & $3.2 \pm 0.9$ & $2.7 \pm 0.8$ & 0.004 \\
\hline Strain based & $2.8 \pm 0.9$ & $2.6 \pm 0.8$ & 0.15 \\
\hline Behavior based & $2.9 \pm 0.8$ & $2.8 \pm 0.8$ & 0.70 \\
\hline
\end{tabular}

SD: standard deviation.

TABLE 5: Gender and work-family conflict in emergency physicians.

\begin{tabular}{|c|c|c|c|}
\hline Work-family conflict & $\begin{array}{c}\text { Male } \\
\text { Mean } \pm \text { SD }\end{array}$ & $\begin{array}{c}\text { Female } \\
\text { Mean } \pm \text { SD }\end{array}$ & $\mathrm{p}$ \\
\hline Work interference with family (WIF) & $3.3 \pm 0.7$ & $3.5 \pm 0.6$ & 0.25 \\
\hline Time based & $3.5 \pm 0.9$ & $3.9 \pm 0.6$ & 0.012 \\
\hline Strain based & $3.4 \pm 0.9$ & $3.7 \pm 0.8$ & 0.11 \\
\hline Behavior based & $3.1 \pm 0.8$ & $3.0 \pm 0.8$ & 0.4 \\
\hline Family interference with work (FIW) & $2.7 \pm 0.7$ & $2.8 \pm 0.6$ & 0.90 \\
\hline Time based & $2.8 \pm 0.8$ & $2.9 \pm 0.8$ & 0.62 \\
\hline Strain based & $2.6 \pm 0.8$ & $2.8 \pm 0.8$ & 0.32 \\
\hline Behavior based & $2.9 \pm 0.8$ & $2.7 \pm 0.7$ & 0.34 \\
\hline
\end{tabular}

SD: standard deviation.

TABLE 6: Logistic regression analysis of factors associated with intention to leave (ITL).

\begin{tabular}{|c|c|c|c|}
\hline Variables & Adjusted odds ratio & $95 \% \mathrm{CI}$ & $\mathbf{P}$ \\
\hline Retirement age preference (years) $\leq 45$ & 10.51 & $3.99-27.68$ & $<0.001$ \\
\hline Night/day shift ratio $>\mathbf{4 0} \%$ & 2.70 & $1.11-6.57$ & 0.029 \\
\hline Family interference with work (FIW), time based & 4.56 & $1.68-12.37$ & 0.003 \\
\hline
\end{tabular}

CI: confidence interval.

TABLE 7: Logistic regression analysis of factors associated with gender differences.

\begin{tabular}{lccc}
\hline Variables & Adjusted odds ratio & 95\% CI & P \\
\hline Age group (years old) $\leq \mathbf{3 5}$ & 3.17 & $1.10-9.11$ & 0.032 \\
Shift length $\mathbf{1 2}$ h & 5.67 & $1.96-16.39$ & 0.001 \\
With Children & 0.18 & $0.06-0.52$ & 0.001 \\
\hline
\end{tabular}

CI: confidence interval.

In our study, EPs below 35 years of age were more likely to leave ED practice; this is in agreement with the finding of highest annualized attrition rates of EPs for the first 5 years after graduation [12]; however, it is not consistent with the findings of the previous SESMAT study, which showed that young age was not linked with ITL [7]. We found that EPs who planned to retire before 45 years of age accounted for a significantly high percentage in the group with ITL within one year $(41.2 \%$ versus $8.5 \%, \mathrm{p}<0.001)$; this revealed that EPs who prefer to retire earlier were also bearing a high risk of job turnover.
Some factors related to ITL of EPs have been discussed, including teamwork, burnout, and job satisfaction. Low quality of teamwork caused a 4-fold increase in ITL, while burnout doubled the risk of ITL for EPs [7]. EPs were found to have the highest rate of burnout (65\%) compared with physicians in general, and $60 \%$ of EPs had moderate-tohigh burnout scores $[6,8,22,23]$. Physicians planning to leave practice were more likely to report feeling of burnout and have lower practice satisfaction $[6,19]$. Despite the high level of burnout, job satisfaction was also reportedly high among EPs in previous studies. More than three-fourths of 
EPs stated that emergency medicine has met or exceeded their career expectations [21, 22]. However, the situation varied in different countries and regions. Chinese EPs had only a moderate level of job satisfaction and were generally not satisfied with their work [5], and job satisfaction was an influencing factor of turnover intention [24].

Schedule flexibility is a key determinant of choosing a career in emergency medicine and ongoing career satisfaction [25]. Excessive clinical workload and night shifts were associated with burnout $[6,20,22,26]$. Higher levels of burnout were noted among EPs whose practices were primarily clinical, and the levels of burnout peaked at 13-15 shifts per month [6]. Physicians who do not have enough time for personal life are three times as likely to report low career satisfaction and twice as likely to experience burnout [21]. Women physicians are more likely to alter their job responsibilities for the benefit of their families and children, with the most common adjustment being reduced working hours [27].

Rotating shifts, including night shifts and weekend shifts, allow for the around-the-clock operation of the emergency room. However, EPs working night shifts were found to have decreased sleep, negative mood states, and poor performance compared to EPs working day shifts [28-30]. Working five consecutive night shifts results in a substantial decline of cognitive performance in EPs [31]. Despite the negative effects of excessive work hours and night shifts on EPs, clinical work hours and night shifts were not found to be related to ITL in French SESMAT [7]. Our study revealed that EPs consider leaving their job when night shifts account for over $40 \%$ of their total shifts. Strategies for enhancing adaptation to night shifts, such as clockwise shift rotations [32-34], rotating shifts after 2-week periods, and an average of 2 days off per week, were suggested [34]. Interventions for enhancing the adaptation of EPs to night shifts and rotations need more research.

Fair and high financial compensation were associated with high career satisfaction, and dissatisfaction with pay was significantly related to ITL $[7,21]$. The result was also noted in our study group.

EPs who were married and had children were less likely to leave their job; the trend was in agreement with a previous report [7]. The possible explanation may be the impacts of financial obligations associated with career alterations on family and children, which made EPs continue their practice. Other factors linked to ITL include worries about making mistakes, absence of continuing education, harassment by superiors, and relationships with administration [7].

4.2. The Gender Differences. Male EPs seemed to remain in their specialties longer than female EPs [11]. In our study, female EPs had shorter ED practice duration, and more than $70 \%$ were less than 35 years. Female EPs in our study were younger than male EPs in Taiwan and their female counterparts in USA [35]. The attrition rate of female EPs remained unclear; however, younger age may be associated with a higher attrition rate and a shorter career span in them. Compared to male EPs, a significantly higher percentage of female EPs reported ITL (32.1\% versus $12.9 \%, \mathrm{p}<0.01)$ in our study. The gender differences on ITL of EPs were not noted in previous studies conducted in other regions [7]. The majority of the female EPs were without children, which was the opposite condition compared to male group. The result is consistent with that of a previous study [35]. Taking care of family and young children is still mostly a woman's responsibility in Asia; this may force female EPs to leave or alter their work before they became as experienced as male EPs.

The gender differences on burnout score varied in different studies [7]. Career satisfaction did not differ between male and female EPs $[6,20,21]$. Schedule flexibility, fairness in financial compensation, and opportunities for career advancement were key factors in career satisfaction among female EPs [35].

4.3. The Work-Family Interference in Emergency Physicians. Conflicts occurred when expectations and demands at either work or in the family were not met. High work-family conflict is a major factor associated with burnout of EPs and remains the highest risk factor of burnout for female EPs $[7,36]$. In addition, higher levels of work-family conflict were associated with higher odds of preferring partial or full retirement within 10 years in both male and female EPs [37], and work-family conflict significantly was related to ITL $[7,22,38,39]$. Studies on the relationship between workfamily conflict and ITL of EPs are limited. In our survey, a significant high level of work interference with family was noted in EPs with ITL. The result is consistent with previous research, which showed that the work-to-family conflict (but not family-to-work conflict) was positively related to ITL $[38,39]$. This could be explained by family boundaries being more permeable than work boundaries, which had made the work-to-family conflict more prevalent [40].

In reviewing the three dimensions of work-family conflict, time-based interference was significantly higher on both WIF scale and FIW scale on ITL of all EPs and on WIF scale of female EPs. Employees with more work hours a week had higher work-family conflict (WFC) and higher end-ofworkday strain [41]. Higher WFC was noted in EPs who were unsatisfied with clinical working hours and night shifts. Employees who were offered greater work-time control and flexibility had lower odds of turnover [42].

Previous studies revealed conflicting results about gender differences on work-family conflict; some showed higher level of WFC in female physicians [43-45], while some reported no significant differences between male and female EPs $[38,46]$. Our survey showed higher scores for female EPs in both WIF scale and FIW scale; however, the result is not significant. However, considering younger age, shortened practice duration, lower rates of having children, and higher ITL in female EPs, we should pay attention to the possibility of female EPs who experienced more work-family conflicts, failed to construct coping strategies, and left clinical practice. Further studies focusing on these issues are warranted.

4.4. Limitation. Several limitations of the study shall be acknowledged. First, the cross-sectional design of the current study has resulted in the low possibility to draw causal 
relations among work-family conflict, gender difference, and intention to leave. Second, as in other questionnaire surveys, response bias could exist. It is possible that those with stronger opinions and those with higher motivations responded and completed the survey.

\section{Conclusion}

Our studies showed that work schedule satisfaction, including clinical work hours and night/day shift ratio, was strongly related to ITL. Females and EPs with higher level of work interference with family scale were more likely to have ITL. On reviewing the work-family conflict three-dimensionally, time-based interference was significantly higher on both WIF scale and FIW scale on ITL of EPs and on WIF scale of female EPs. For both male and female EPs, time remains a critical and important issue when trying to construct strategies to maintain ED clinical practice as an entire career.

Further studies should focus on developing strategies on the schedule arrangement to minimize the work stress and work-family conflicts for both females and males.

\section{Data Availability}

Due to the sensitive nature of the questions asked in this study, survey respondents were assured that raw data would remain confidential and would not be shared. Data is not available/the data that has been used is confidential.

\section{Conflicts of Interest}

There are no conflicts of interest associated with this study.

\section{Authors' Contributions}

Yi-Fang Wu, Po-Chang Wang, and Yi-Chuan Chen conceptualized the study, designed the method, supervised the data collection, undertook the recruitment of participating centers and patients and managed the data, including quality control, and drafted the manuscript, and all authors contributed substantially to its revision. Yi-Chuan Chen takes responsibility for the paper as a whole and provided statistical advice on study design and analyzed the data; Yi-Fang Wu chaired the data oversight committee.

\section{Acknowledgments}

This research was supported by the Emergency Care Foundation and the Taiwan Academy of Emergency Department Management.

\section{References}

[1] A. E. Klasner, "Attrition rates of Pediatric Emergency Medicine fellowship graduates," Journal of Investigative Medicine, vol. 59, no. 6, pp. 964-965, 2011.

[2] J. Wasserberger and G. J. Ordog, "Is emergency medicine built to self destruct by 1992?" Annals of Emergency Medicine, vol. 15, no. 5, pp. 603-604, 1986.
[3] S. P. Ros and R. Scheper, "Career longevity in clinical pediatric emergency medicine," Pediatric Emergency Care, vol. 25, no. 8, pp. 487-488, 2009.

[4] J. D. Leitzell, “An Uncertain Future," The New England Journal of Medicine, vol. 304, no. 8, pp. 477-480, 1981.

[5] Y. Xiao, J. Wang, S. Chen et al., "Psychological distress, burnout level and job satisfaction in emergency medicine: A crosssectional study of physicians in China," EMA - Emergency Medicine Australasia, vol. 26, no. 6, pp. 538-542, 2014.

[6] R. Goldberg, R. W. Boss, L. Chan et al., "Burnout and its correlates in emergency physicians: Four years' experience with a wellness booth," Academic Emergency Medicine, vol. 3, no. 12, pp. 1156-1164, 1996.

[7] M. Estryn-Behar, M.-A. Doppia, K. Guetarni et al., "Emergency physicians accumulate more stress factors than other physicianse - Results from the French SESMAT study," Emergency Medicine Journal, vol. 28, no. 5, pp. 397-410, 2011.

[8] T. D. Shanafelt, S. Boone, L. Tan et al., "Burnout and satisfaction with work-life balance among US physicians relative to the general US population," JAMA Internal Medicine, vol. 172, no. 18, pp. 1377-1385, 2012.

[9] G. Kuhn, R. Goldberg, and S. Compton, "Tolerance for Uncertainty, Burnout, and Satisfaction With the Career of Emergency Medicine," Annals of Emergency Medicine, vol. 54, no. 1, pp. 106e6, 2009.

[10] H. D. Crook, D. M. Taylor, J. F. Pallant, and P. A. Cameron, "Workplace factors leading to planned reduction of clinical work among emergency physicians," EMA - Emergency Medicine Australasia, vol. 16, no. 1, pp. 28-34, 2004.

[11] Y.-K. Lee, C.-C. Lee, C.-C. Chen, C.-H. Wong, and Y.-C. Su, "High risk of 'failure' among emergency physicians compared with other specialists: A nationwide cohort study," Emergency Medicine Journal, vol. 30, no. 8, pp. 620-622, 2013.

[12] A. A. Ginde, A. F. Sullivan, and C. A. Camargo Jr., "Attrition from emergency medicine clinical practice in the United States," Annals of Emergency Medicine, vol. 56, no. 2, pp. 166-171, 2010.

[13] N. bu and C. A. Mckeen, "Work and family expectations of the future managers and professionals of Canada and China," Journal of Managerial Psychology, vol. 15, no. 8, pp. 771-794, 2000.

[14] D. S. Carlson, K. M. Kacmar, and L. J. Williams, "Construction and Initial Validation of a Multidimensional Measure of WorkFamily Conflict," Journal of Vocational Behavior, vol. 56, no. 2, pp. 249-276, 2000.

[15] L. lu, R. Gilmour, S.-F. Kao, and M.-T. Huang, "A crosscultural study of work/family demands, work/family conflict and wellbeing: The Taiwanese vs British," Career Development International, vol. 11, no. 1, pp. 9-27, 2006.

[16] L. Lu, S.-F. Kao, C. L. Cooper et al., "Work Resources, Workto-Family Conflict, and Its Consequences: A Taiwanese-British Cross-Cultural Comparison," International Journal of Stress Management, vol. 16, no. 1, pp. 25-44, 2009.

[17] N. K. Dhand and M. S. Khatkar, "Statulator: An online statistical calculator. Sample Size Calculator for Comparing Two Independent Proportions," http://statulator.com/SampleSize/ ss2P.htmlat.

[18] D. W. Hosmer and S. Lemeshow, "Applied Logistic Regression," in John Wiley \& Sons, Inc, pp. 156-164, 2000.

[19] M. E. Gallery, T. W. Whitley, L. K. Klonis, R. K. Anzinger, and D. A. Revicki, "A study of occupational stress and depression among emergency physicians," Annals of Emergency Medicine, vol. 21, no. 1, pp. 58-64, 1992. 
[20] L. Doan-Wiggins, L. Zun, M. A. Cooper, D. L. Meyers, E. H. Chen, and F. T. W. T. Force, "Practice Satisfaction, Occupational Stress, and Attrition of Emergency Physicians," Academic Emergency Medicine, vol. 2, no. 6, pp. 556-563, 1995.

[21] R. K. Cydulka and R. Korte, "Career Satisfaction in Emergency Medicine: The ABEM Longitudinal Study of Emergency Physicians," Annals of Emergency Medicine, vol. 51, no. 6, pp. 714-e1, 2008.

[22] S. Lloyd, D. Streiner, and S. Shannon, "Burnout, depression, life and job satisfaction among Canadian emergency physicians," The Journal of Emergency Medicine, vol. 12, no. 4, pp. 559-565, 1994.

[23] M. Arora, S. Asha, J. Chinnappa, and A. D. Diwan, "Review article: Burnout in emergency medicine physicians," EMA Emergency Medicine Australasia, vol. 25, no. 6, pp. 491-495, 2013.

[24] Y. Lu, X. Hu, X. Huang et al., "The relationship between job satisfaction, work stress, work-family conflict, and turnover intention among physicians in Guangdong, China: a crosssectional study," BMJ Open, vol. 7, no. 5, p. e014894, 2017.

[25] A. A. Kazzi, M. I. Langdorf, D. Ghadishah, and N. Handly, "Motivations for a career in emergency medicine: A profile of the 1996 US applicant pool," Canadian Journal of Emergency Medicine, vol. 3, no. 2, pp. 99-104, 2001.

[26] K. N. Hall and M. A. Wakeman, "Residency-trained emergency physicians: Their demographics, practice evolution, and attrition from emergency medicine," The Journal of Emergency Medicine, vol. 17, no. 1, pp. 7-15, 1999.

[27] G. Verlander, "Female physicians: Balancing career and family," Academic Psychiatry, vol. 28, no. 4, pp. 331-336, 2004.

[28] R. Smith-Coggins, M. R. Rosekind, S. Hurd, and K. R. Buccino, "Relationship of day versus night sleep to physician performance and mood," Annals of Emergency Medicine, vol. 24, no. 5, pp. 928-934, 1994.

[29] R. Smith-Coggins, M. R. Rosekind, K. R. Buccino, D. F. Dinges, and R. P. Moser, "Rotating shiftwork schedules: Can we enhance physician adaptation to night shifts?" Academic Emergency Medicine, vol. 4, no. 10, pp. 951-961, 1997.

[30] R. Smith-Coggins, K. B. Broderick, and C. A. Marco, "Night shifts in emergency medicine: The American Board of Emergency Medicine Longitudinal Study of Emergency Physicians," The Journal of Emergency Medicine, vol. 47, no. 3, pp. 372-378, 2014.

[31] D. J. Dula, N. L. Dula, C. Hamrick, and G. C. Wood, “The effect of working serial night shifts on the cognitive functioning of emergency physicians," Annals of Emergency Medicine, vol. 38, no. 2, pp. 152-155, 2001.

[32] F. W. Turek, "Circadian principles and design of rotating shift work schedules," American Journal of Physiology-Regulatory, Integrative and Comparative Physiology, vol. 251, no. 3, pp. R636-R638, 1986.

[33] C. A. Czeisler, M. C. Moore-Ede, and R. M. Coleman, "Rotating shift work schedules that disrupt sleep are improved by applying orcadian principles," Science, vol. 217, no. 4558, pp. 460-463, 1982.

[34] M. Kostreva, E. McNelis, and E. Clemens, "Using a circadian rhythms model to evaluate shift schedules," Ergonomics, vol. 45, no. 11, pp. 739-763, 2002.

[35] K. J. Clem, S. B. Promes, S. W. Glickman et al., "Factors Enhancing Career Satisfaction Among Female Emergency Physicians," Annals of Emergency Medicine, vol. 51, no. 6, pp. 723-e8, 2008.
[36] Y. Wang, L. Liu, J. Wang, and L. Wang, "Work-family Conflict and Burnout among Chinese Doctors: The Mediating Role of Psychological Capital," Journal of Occupational Health, vol. 54, no. 3, pp. 232-240, 2012.

[37] J. M. Raymo and M. M. Sweeney, "Work-Family Conflict and Retirement Preferences," The Journals of Gerontology Series B: Psychological Sciences and Social Sciences, vol. 61, no. 3, pp. S161S169, 2006.

[38] J. H. Greenhaus, S. Parasuraman, and K. M. Collins, "Career involvement and family involvement as moderators of relationships between work-family conflict and withdrawal from a profession.", Journal of Occupational Health Psychology, vol. 6, no. 2, pp. 91-100, 2001.

[39] I. Fuß, M. Nübling, H.-M. Hasselhorn, D. Schwappach, and M. A. Rieger, "Working conditions and work-family conflict in German hospital physicians: Psychosocial and organisational predictors and consequences," BMC Public Health, vol. 8, 2008.

[40] M. R. Frone, M. Russell, and M. L. Cooper, "Prevalence of work-family conflict: Are work and family boundaries asymmetrically permeable?" Journal of Organizational Behavior, vol. 13, no. 7, pp. 723-729, 1992.

[41] R. A. Matthews, C. A. Swody, and J. L. Barnes-Farrell, "Work hours and work-family conflict: The double-edged sword of involvement in work and family," Stress and Health, vol. 28, no. 3, pp. 234-247, 2012.

[42] P. Moen, E. L. Kelly, and R. Hill, "Does enhancing work-time control and flexibility reduce turnover? A naturally occurring experiment," Social Problems, vol. 58, no. 1, pp. 69-98, 2011.

[43] Y. Treister-Goltzman and R. Peleg, "Female Physicians and the Work-Family Conflict," The Israel Medical Association Journal (IMAJ), vol. 18, no. 5, pp. 261-266, 2016.

[44] Á. Szilvia, G. Zsuzsa, and L. Krisztina, "High prevalence of job dissatisfaction among female physicians: Work-family confl ict as a potential stressor," Orvosi Hetilap, vol. 150, no. 31, pp. 14511456, 2009.

[45] S. Adám, "High prevalence of work-family conflict among female physicians: Lack of social support as a potential antecedent," Orvosi Hetilap, vol. 150, no. 50, pp. 2274-2281, 2009.

[46] S. Mache, M. Bernburg, K. Vitzthum, D. A. Groneberg, B. F. Klapp, and G. Danzer, "Managing work-family conflict in the medical profession: working conditions and individual resources as related factors," BMJ Open, vol. 5, no. 4, p. e006871, 2015. 


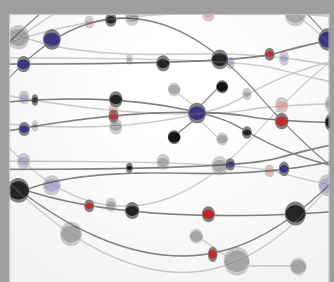

The Scientific World Journal
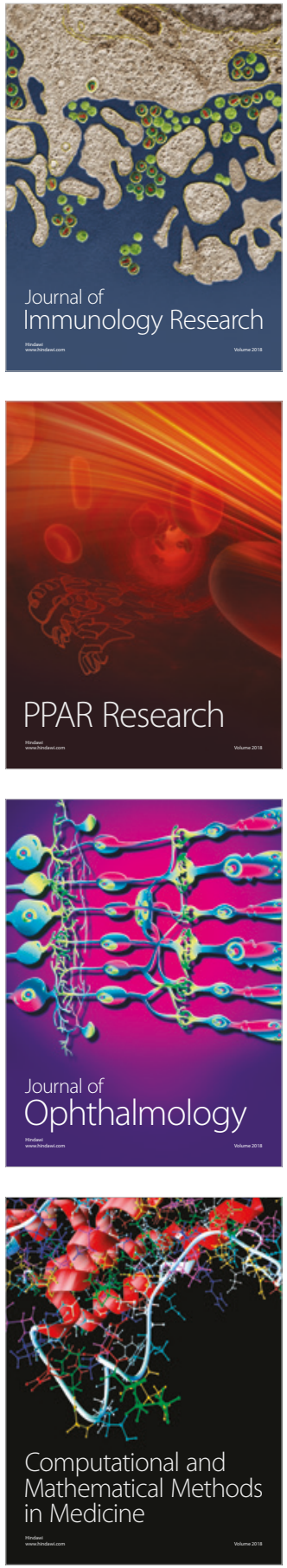

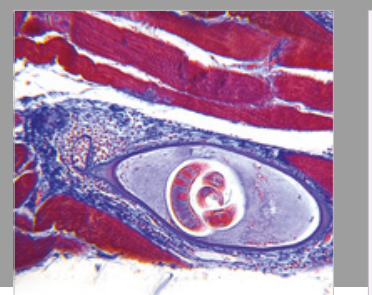

Gastroenterology Research and Practice

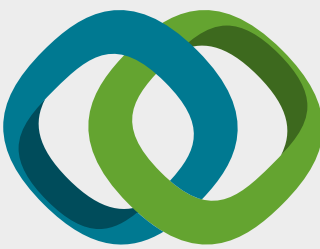

\section{Hindawi}

Submit your manuscripts at

www.hindawi.com
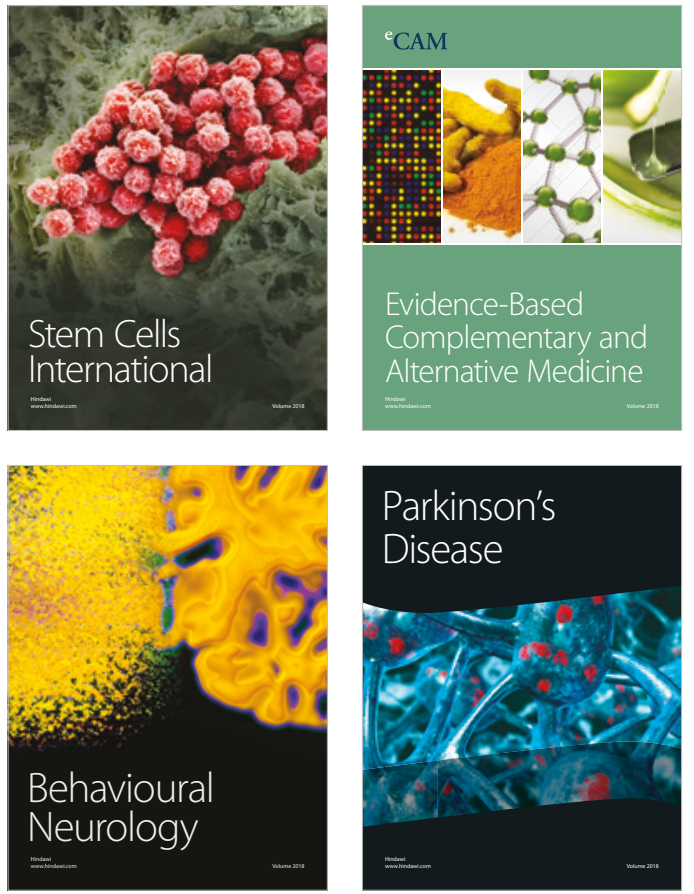

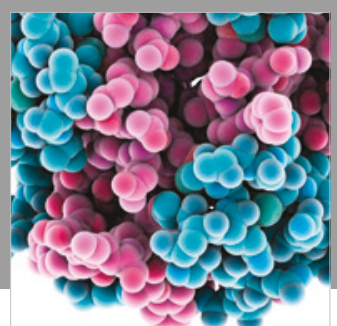

ournal of

Diabetes Research

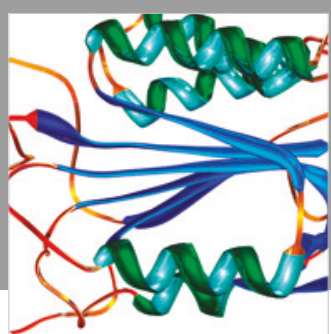

Disease Markers
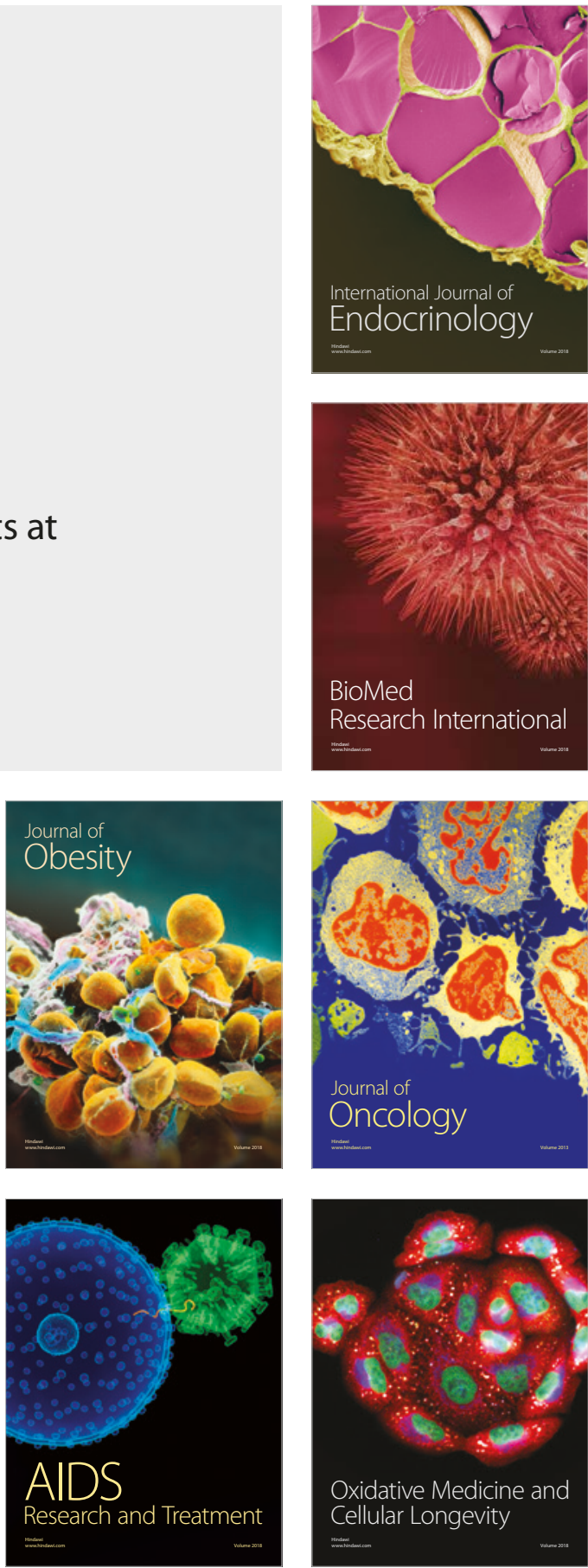